\title{
Mental health outcomes of COVID-19 quarantine in the Kurdistan Region of Iraq: A Case-Control Study
}

\author{
Pegah AM Seidi, ${ }^{1 *}$ Aram SMA Kamali, ${ }^{2}$ Maryam Didehdar Ardabil, ${ }^{3}$ Ismail Ahmed Ali, ${ }^{4}$ Dilshad Jaff ${ }^{5}$ \\ ${ }^{I}$ Research Center, University of Garmian, Kalar, Kurdistan Region, Iraq \\ ${ }^{2}$ Directorate of Health, Garmian Administration, Kalar, Kurdistan Region, Iraq \\ ${ }^{3}$ Independent Researcher, Tehran, Iran \\ ${ }^{4}$ Shahid Aso Hospital, Slemani Directorate of Health, Slemani, Kurdistan Region, Iraq \\ ${ }^{5}$ Department of Maternal and Child Health, Gillings School of Global Public Health, University of North Carolina at Chapel Hill, NC, USA.
}

Received 18 January 2021; revised 18 January 2021;

accepted 18 May 2021; available online 09 June 2021

doi:10.24271/psr.25

\begin{abstract}
This study was designed to evaluate the association of COVID-19 quarantine with the mental health outcomes in the Kurdistan region of Iraq according to key measures of this study. We conducted a matched case-control study within the cohort of all quarantined persons from February 22 through March 31, $2020(\mathrm{n}=300)$ in Kurdistan region of Iraq. Participants were matched on gender, age, marital status, and education level. Mental health outcomes measured by General Health Questioner (GHQ-28), Impact of event scale revised (IES-R), and Fear of COVID-19(FC-19S) using an online form. Data analyzed with a t-test and Multiple Regression analysis (confidence intervals=99\%). The final study sample included 102 cases and 106 controls, (69\% participation rate). Cases showed significantly higher scores in general health questionnaire $(\mathrm{t}=4.57, \mathrm{P}<0.001)$ and its components (anxiety /insomnia, somatic syndrome, social dysfunction $[\mathrm{P}<0.001])$, Post-traumatic symptoms $(\mathrm{t}=6.25, \mathrm{P}<0.001)$, and Fear of COVID-2019 ( $\mathrm{t}=3.04, \mathrm{P}<0.001)$. The groups were not significantly different in the case of depression $(\mathrm{t}=1.95, \mathrm{P}=0.06)$. Multivariable logistic regression analysis showed that after controlling for confounders (age, gender, education) mental health predicted with PTSD (OR,1;95\%CI,0.45-0.78; P=.0001) and fear of COVID19(OR,0.55;95\%CI,0.73-0.33; P=.0001). These findings suggest that quarantine significantly contributed to negative mental health outcomes in the Kurdistan region of Iraq where people are already affected by other stressors. These findings may inform decision and public health policy makers to prevent psychological complications while designing and applying measures in the face of other major public health emergencies.
\end{abstract}

(C) 2021 Production by the University of Garmian. This is an open access article under the LICENSE

https://creativecommons.org/licenses/by-nc/4.0/

Keywords: quarantine; COVID-2019; mental health

\section{Introduction}

In December 2019 coronavirus disease (COVID-19) started in Wuhan-China and spread widely around the world. ${ }^{1}$ On March 2020, the World Health Organization (WHO) called all countries to take measures to limit the spread of the virus. ${ }^{2}$ As a result, many states imposed quarantine on travels coming from infected areas. ${ }^{3}$ Iraq, neighboring two highly infected countries, Iran and Turkey, implemented quarantine on travelers coming back from abroad particularly these two countries. By early June 2020, 11,098 cases were confirmed and 318 persons had died in Iraq, among them 1222 confirmed cases and 24 deaths in the Kurdistan Region of Iraq (KRI). ${ }^{4,5}$

* Corresponding author

E-mail address: pegah.am.seidi@garmian.edu.krd (Instructor).

Peer-reviewed under the responsibility of the University of Garmian.
Although the number of confirmed cases and died people are less than many other countries and regions, because of the ongoing instability, presence of large vulnerable populations, such as forcibly displaced persons, and the weak health system, the KRI health authorities announced measures to prevent the spread of the virus in the region, which included border closures and the establishment of different quarantine sites to accommodate travelers returning from abroad for 14 days. ${ }^{6}$

Quarantine eventually is an unpleasant experience for those who undergo it. ${ }^{7}$ Separation from loved ones, the loss of freedom, uncertainty over disease status, ${ }^{8}$ boredom and even in some cases suicide ideation/attempt ${ }^{9}$ create dramatic effects. It is reported that quarantine could let several negative emotions. ${ }^{7,} 10,11$ However, in case of predictors of psychological problems during quarantine there are contradicting findings. ${ }^{12,10}$ To our knowledge, there is no information available about the psychological impacts of quarantine specially in the KRI where most of the population is afflicted by conflict and political 
upheavals. It is documented that people in such settings are already in need for receiving mental health services. ${ }^{13}$ Findings by local researchers are in agreement with these reports. ${ }^{14,15}$ In addition to ongoing stressors and the weak health system, stigma is a major barrier for the population to seek mental health services in the region. ${ }^{16}$ When not addressed, these stressors and problems will have long-term impact on the population.

Our aim in the current study was to investigate the association between quarantine and mental health outcomes for the following reasons: First, there is lack of information about psychological conditions of under quarantine cases during the COVID-19 pandemic in the Middle East generally and in Iraq specifically; ${ }^{17}$ Second, studies have focused on the mental health outcomes in healthcare providers, patients and the public while quarantined individuals are overlooked. In this study we hypothesized that quarantine may affected mental health outcomes of quarantined persons.

\section{Methods}

\section{1. Study setting and date}

A case-control study conducted within a cohort of all quarantined persons and controls in Garmian Region of KRI close to the IranIraq border between February 22 to March 31, 2020. The quarantine center was a hotel designated by the authorities located in Kalar city. Under quarantined individuals were instructed not to leave the hotel, wash their hands frequently, and wear masks and gloves when they are not in their rooms. In addition, their body temperature, obligatory, blood glucose and blood pressure, optional, were measured twice a day.

\section{2. Participants}

Sample consists of two groups:

a. Cases: Of 150 quarantined individuals we recruited 102 cases, 36 females and 66 males, who met inclusion criteria, with mean age of $31.75 \pm 6.34$.

b. Control: Of 150 non-quarantined individuals, we purposively recruited 106 controls, 46 females and 60 males, who met inclusion criteria, with mean age of $30.08 \pm 6.48$. They were matched according to gender, age, marital status, and education level with cases.

Most of the quarantined cases were Iraqi students in Iranian Universities who returned home due to the spread of COVID19 in Iran. The out of quarantine participants were staff and students from universities in the KRI who completed questionnaires with a similar procedure as the quarantined samples.

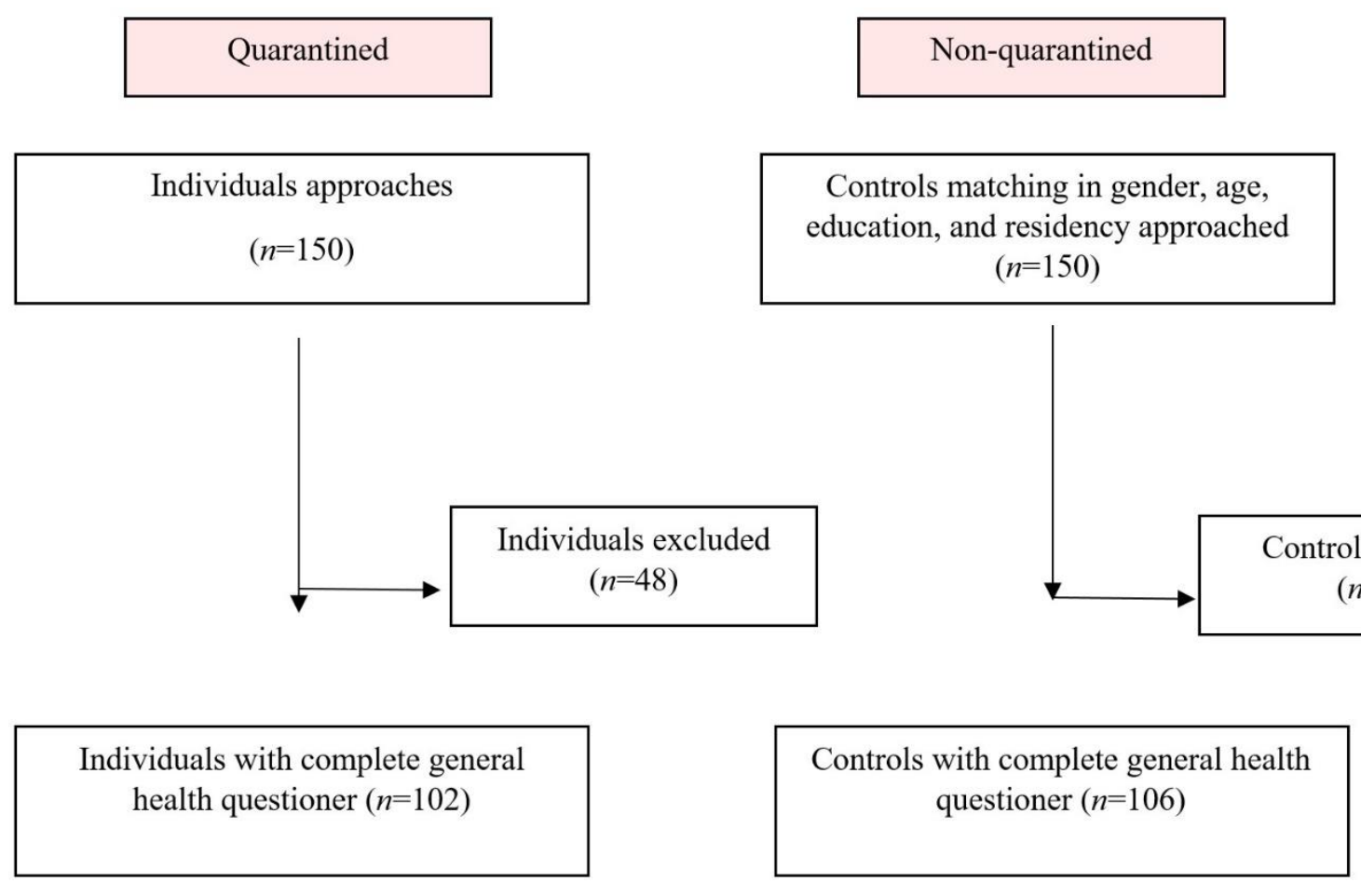

Figure 1: Flow chart depicting enrolment of quarantined individuals and non-quarantined controls.

\section{3. Inclusion and exclusion criteria}

Inclusion criteria were Iraqi citizenship, educated at least up to high school, completed at least seven consecutive days in quarantine at the designated center, being medically stable, no obvious signs of illness or injury indicating a need for immediate medical attention, not being diagnosed with a psychotic disorder. Participants were informed about the study using a detailed phone-call. The individuals who replied were contacted for online consent with no further contact with those who didn't reply. The response rate was $69 \%$.

\section{4. Outcome Measures}

Mental health outcomes were investigated using these measures: General Health Questionnaire-28 (GHQ-28), Impact of Event Scale-Revised (IES-R), and Fear of COVID-19 Scale (FC-19S). GHQ-28 is a self-administrated screening tool designed to detect current mental disturbances and disorders. It has four 
components, somatic symptoms; anxiety/insomnia; social dysfunction, and depression. A higher score represents poorer mental health and a total score of $23 / 24$ is the threshold for the presence of distress. The GHQ-28 is a valid and reliable tool for screening mental health in Kurdish communities. ${ }^{18}$ Cronbach Alpha for GHQ-24 in this study was 0.87. The IES-R scale is a self-report questionnaire, which includes 22 items and three components: intrusion, avoidance, and hyperarousal. ${ }^{19}$ It is an appropriate instrument to measure the symptoms of PostTraumatic Stress Disorder (PTSD) in adult populations with cutoff score of 33 or above. ${ }^{20}$ The Kurdish version is validated and used in another study in the KRI. ${ }^{21}$ Cronbach Alpha showed appropriate internal consistency for this study (0.70). FC-19S include seven items and participants should indicate their level of agreement with its statements using a five-item Likert-type scale. The higher total score, represents the greater fear of coronavirus19. The validity procedure of this scale showed a stable unidimensional structure with robust psychometric properties. ${ }^{22}$ The translation process for Kurdish version was performed according to the Functional Assessment of Chronic Illness Therapy translation methodology (FACIT), as a standard methodology. ${ }^{23}$ Obtained Cronbach Alpha for this study was 0.67

Besides these measures, a demographic data questionnaire was developed to cover basic demographic variables, which included being quarantined or non-quarantined, gender, age, marital status, education, origin, destination, days in quarantine, whether you contacted with an infected patient? do you think quarantine is necessary for your case?

\section{5. Procedure and Ethical considerations}

In line with the Garmian Directorate of Health guidelines, and in order to prevent person-to-person contact, private online questionnaires developed and sent via email or Facebook Messenger to participants through KoBo Toolbox, a free opensource tool for data collection using mobile phones, tablets, computers as well as paper. The corresponding researcher was available on-call during the data collection to answering questions. Ethical Committee of Research Center at the University of Garmian in cooperation with Garmian Directorate of Health approved the current study on March 9th (approval number EC-G/201). On first page of the questionnaire, a privacy statement, right to refuse to participation, aims of the study and contact numbers of corresponding researcher were provided. All participants signed consent forms electronically before completing the questionnaires. Data was stored on a secured computer.

\section{6. Statistical analysis}

The collected data scored and entered into PSS-20. The mean and standard deviation of mental health with its components [somatic symptoms; anxiety/insomnia; social dysfunction, and depression], post-traumatic symptoms with its components [intrusion, avoidance, and hyperarousal], and fear of COVID-19, were investigated for both groups. The normal distribution of quantitative data was investigated by applying KolmogorovSmirnov test. The GHQ-28 and IES-R global and their components scores, and fear COVID-2019 were compared between groups by independent t-test for groups. Chi-square conducted for continuous and categorical data. Cronbach's $\alpha$ coefficient was calculated to examine IES-R, GHQ-28, and FC19S inter-item internal consistency. The Fear of COVID-2019, post-traumatic symptoms, and mental health relationship analyzed through regression. An effect size (ES) of $0.10,0.30$, and 0.50 was considered small, medium, and large. The statistical significance was set at $\mathrm{p}<.001$.

\section{Results and Discussion}

\section{1. Demographic Characteristics}

Of the 300 approached participants (150 quarantined and 150 non-quarantined) 106 non-quarantined cases (70.66\%) and 102 quarantined cases $(68 \%)$ participated in the study. From the data, $59.61 \%$ of the participants were male and the rest were female. The majority of participants were married (65.86\%). More than half of participants $(63.94 \%)$ were master graduate or master's student, $20.67 \%$ bachelor graduate or last year student and rest were PhD/PMD student or graduate. Demographic characters of participants compared in Table 1 .

Table 1: Demographic characters of participants

\begin{tabular}{|c|c|c|c|c|}
\hline \multirow{2}{*}{ Variable } & & Non-Quarantined & Quarantined & \multirow[t]{2}{*}{ Result } \\
\hline & & $\mathbf{N}(\%)$ & $\mathbf{N}(\%)$ & \\
\hline \multirow[t]{3}{*}{ Education } & Bachelor & $28(26.4)$ & $15(14.7)$ & \multirow{3}{*}{$\begin{array}{l}\chi 2=4.87 \\
P \text {-value }=0.08\end{array}$} \\
\hline & Master & $61(57.5)$ & $72(70.6)$ & \\
\hline & $\mathrm{PhD}$ & $17(16.00)$ & $15(14.7)$ & \\
\hline \multirow[t]{3}{*}{ Age } & $19-25$ & $24(20.8)$ & $30(29.4)$ & \multirow{3}{*}{$\begin{array}{l}\chi 2=2.64 \\
P \text {-value }=0.26\end{array}$} \\
\hline & $26-30$ & $20(18.9)$ & $21(20.6)$ & \\
\hline & $31-38$ & $64(60.4)$ & $51(50)$ & \\
\hline \multirow[t]{2}{*}{ Marriage } & Married & $67(63.2)$ & $70(86.6)$ & \multirow{2}{*}{$\begin{array}{l}\chi 2=0.67 \\
P \text {-value }=0.41\end{array}$} \\
\hline & single & $39(36.8)$ & $32(31.4)$ & \\
\hline \multirow[t]{2}{*}{ Gender } & Male & $60(56.6)$ & $64(64.7)$ & \multirow{2}{*}{$\begin{array}{l}\chi 2=1.42 \\
P \text {-value }=0.14\end{array}$} \\
\hline & female & $46(43.4)$ & $38(35.3)$ & \\
\hline Age & Mean \pm SD & $31.75 \pm 6.34$ & $30.08 \pm 6.48$ & $\mathrm{t}=1.94, \mathrm{P}=0.06$ \\
\hline
\end{tabular}


(11.89 [3.93]), social dysfunction (8.49 [3.04]), mental health problems (40.92 [12.40]), Post-traumatic symptoms (39.19 [9.75]), and fear of COVID-19 (13.89 [2.90]). These differences were significant for mental health $(\mathrm{t}=4.57, \mathrm{P}<0.001)$ and its components, anxiety /insomnia $(\mathrm{t}=3.57, \mathrm{P}<0.001)$, somatic syndrome $(\mathrm{t}=5.57, \mathrm{P}<0.001)$, and social dysfunction $(\mathrm{t}=3.34$, $\mathrm{P}<0.001)$ in comparison to non-quarantined participants $(\mathrm{P}<0.001)$. The groups were not significantly different in case of depression ( $\mathrm{t}=1.95, \mathrm{P}=0.06)$ (Table2). However, the total score of mental health in both groups was higher than the cut-point
(GHQ>23), which showed more mental health issues in both groups.

In term of Post-traumatic symptoms $(\mathrm{t}=6.25, \mathrm{P}<0.001)$, and its components, avoidance $(\mathrm{t}=5.78, \mathrm{P}<0.001)$, hyperarousal $(\mathrm{t}=3.77$, $\mathrm{P}<0.01)$, and intrusion $(\mathrm{t}=5.06, \mathrm{P}<0.001)$ significant difference observed (Table 2). In addition, Fear of COVID-2019 in quarantined cases significantly were higher than non-quarantined group $(\mathrm{t}=3.04, \mathrm{P}<0.001)$ (Table 2).

Table 2: Results of GHQ-28, IES-r and FC-19S scores of participants in two groups

\begin{tabular}{|c|c|c|c|c|c|c|}
\hline \multicolumn{2}{|c|}{ Variable } & Group & Mean & SD & $\mathbf{T}$ & sig \\
\hline \multirow[t]{10}{*}{ GHQ } & \multirow[t]{2}{*}{ Mental health } & Non-quarantined & 34.70 & 7.21 & \multirow{2}{*}{4.57} & \multirow{2}{*}{$0.001 *$} \\
\hline & & quarantined & 40.92 & 12.40 & & \\
\hline & \multirow[t]{2}{*}{ anxiety/insomnia } & Non-quarantined & 8.76 & 2.60 & \multirow{2}{*}{3.57} & \multirow{2}{*}{$0.001^{*}$} \\
\hline & & quarantined & 10.27 & 3.88 & & \\
\hline & \multirow[t]{2}{*}{ Depression } & Non-quarantined & 9.33 & 3.08 & \multirow{2}{*}{1.95} & \multirow{2}{*}{0.06} \\
\hline & & quarantined & 10.26 & 3.79 & & \\
\hline & \multirow[t]{2}{*}{ Somatic syndrome } & Non-quarantined & 10.04 & 3.50 & \multirow{2}{*}{5.57} & \multirow{2}{*}{$0.001 *$} \\
\hline & & Quarantined & 11.89 & 3.93 & & \\
\hline & \multirow[t]{2}{*}{ Social dysfunction } & Non-quarantined & 6.56 & 1.79 & \multirow{2}{*}{3.34} & \multirow{2}{*}{$0.001 *$} \\
\hline & & Quarantined & 8.49 & 3.04 & & \\
\hline \multirow[t]{8}{*}{ IES-R } & \multirow[t]{2}{*}{ Post-traumatic symptoms } & Non-quarantined & 31.83 & 7.06 & 6.25 & $0.001 *$ \\
\hline & & Quarantined & 39.19 & 9.75 & & \\
\hline & \multirow[t]{2}{*}{ avoidance } & Non-quarantined & 10.22 & 2.74 & 5.78 & $0.001 *$ \\
\hline & & Quarantined & 13.28 & 4.57 & & \\
\hline & \multirow[t]{2}{*}{ hyperarousal } & Non-quarantined & 10.27 & 3.15 & 3.77 & $0.001 *$ \\
\hline & & Quarantined & 11.98 & 3.35 & & \\
\hline & \multirow[t]{2}{*}{ intrusion } & Non-quarantined & 11.33 & 3.62 & 5.06 & $0.001 *$ \\
\hline & & Quarantined & 13.93 & 3.78 & & \\
\hline \multirow[t]{2}{*}{ FC-19S } & \multirow{2}{*}{ Fear of COVID_19 } & Non-quarantined & 12.72 & 2.60 & 3.04 & $0.001 *$ \\
\hline & & Quarantined & 13.89 & 2.90 & & \\
\hline
\end{tabular}

$* \mathbf{P}<\mathbf{0 . 0 0 1}$

While our findings showed a significant difference between mental health outcomes of quarantined and non-quarantined groups, another research reported no significant difference. ${ }^{20}$ It is noteworthy to mention that they investigated home-based quarantine for shorter time while ours was 14 days centralized quarantine. In addition, the differences between these results could be related to basic differences in mental health conditions between the populations in both studies. Researches suggested that people who live in Kurdistan region, generally have more mental health issues due to experiencing conflicts, displacement, violence, and political upheavals. ${ }^{14,24}$ The results of this study also confirm this claim, because the total scores of mental health for non- quarantined group is also higher than the cut-point.

In line with our findings, it was reported that about one-third of quarantined participants reported psychological distress during the quarantine. ${ }^{10}$ Challenges such as sense of isolation, ${ }^{25}$ inadequate supplies of daily needs, inadequate information on dealing with infectious diseases ${ }^{26}$ financial hardships, ${ }^{27}$ fear, anger, and boredom, ${ }^{28}$ during quarantine could trigger common mental disorders, ${ }^{29-31}$ which exceed the consequences of the COVID-19 pandemic itself.

In our research, cases reported higher fear of COVID-19 as most of them were travelers who came from Iran, one of the first five infected countries during our data collection, and had contact with the public in Iran without applying proper protective measures such as social distancing and using face masks. In addition, constant increase in mortality and morbidity from COVID-19 reported in the Iranian news cycle created ambiguity and anxiety in most of the cases. Therefore, they felt more likely at risk of infection.

\section{3. Risk Factors of Mental Health Outcomes}

Multivariable logistic regression analysis showed that, after controlling for confounders such as age, gender, and education, mental health predicted in the participants with post-traumatic symptoms (OR,1;95\%CI,0.45-0.78;P=.0001) and fear of

COVID19(OR,0.55;95\%CI,0.73-0.33;P=.0001) (Table3). 
Table 3: Relationship between mental health, Post-traumatic symptoms and fear of COVID-2019

\begin{tabular}{|l|l|l|l|l|l|l|l|}
\hline Variable & R & Adj R2 & F & B & $\boldsymbol{\beta}$ & t & P \\
\hline Post-traumatic symptoms & 0.51 & 0.26 & 73.76 & 0.58 & 0.51 & 8.85 & $0.001^{*}$ \\
\hline Fear of COVID-2019 & 0.24 & 0.05 & 13.25 & 0.92 & 0.24 & 3.64 & $0.001^{*}$ \\
\hline *P<0.001
\end{tabular}

This implies that people who experienced more traumatic symptoms and higher fear of COVID-19 reported lower mental health as they perceived more distress. ${ }^{32}$ Although both fear of COVID-19 and Post-Traumatic symptoms can predict the mental health outcomes but Post-Traumatic symptoms is a stronger predictor of mental health which is in line with the context of the region of the study.

Despite the fact that quarantine is one of the most effective measures for preventing outbreak of diseases,${ }^{33}$ depriving people from their home and routine may trigger mental health conditions, especially those who have been already affected by other stressors. To mitigate that, some measures could be implemented such as home-based quarantine, disseminating sound and clear information heavily to the public and providing mental health support for the people in need.

\section{Conclusion}

This case-control study establishes an association between quarantine and mental health outcomes. Our findings showed that quarantine triggered mental health distress as the cases reported higher anxiety/insomnia, social dysfunction, somatic syndrome, post-traumatic symptoms, and fear of COVID-19 in comparison to controls. However, no difference has seen in case of depression between the two groups. This concludes that short time stress didn't trigger depression among quarantined participants. According to the results of this study, there was a significant relationship between mental health, Post-Traumatic symptoms and fear of COVID-2019. This study has several limitations which must be pointed out. The mental health status of the samples was not followed up over long time. The sample sizes were small due to the number of travelers that quarantined in the study location. The study mainly included educated individuals which may not correctly represent the mental health status of the general population. There was a lack of standardized survey instruments for psychological responses to quarantine. Despite these limitations, the results of this survey will allow for the generation of hypotheses that require further exploration.

\section{1. Public Health Implications}

Our study provides evidence that quarantine can result in considerable psychological distress in people that have been affected by other stressors. Quarantine plans should be implemented carefully to avoid these negative psychological outcomes. These findings may inform decision and public health policy makers to prevent psychological complications while designing and applying measures in the face of other major public health emergencies.

\section{Authors contribution}

PAMS: Conceptualization; data collection; writing original draft preparation, review and editing. ASMAK: Data collection; data extraction, resources; writing original draft preparation. MDA: designed the search strategy, interpretation of the data, resources, writing original draft preparation. EAA: Data collection; data extraction, resources; writing original draft preparation. DJ: supervision; methodology; interpretation of the data; resources; revise the final draft and editing. Authors certify that the manuscript represents valid work and that neither the submitted manuscript nor one with substantially similar content under their authorship has been published or is being considered for publication elsewhere.

\section{Conflict of interests}

None.

\section{References}

1. Pan, A., Liu, L., Wang, C., et al. Association of Public Health Interventions With the Epidemiology of the COVID-19 Outbreak in Wuhan, China. JAMA. 2020;323(19):1915-1923. doi:10.1001/jama.2020.6130

2. World Health Organization. WHO statement on cases of COVID-19 surpassing 100 000. Accessed March 7, 2020. https://www.who.int/news-room/detail/07-03-2020who-statement-on-cases-of-covid-19-surpassing-100-000

3. Han, Y., Liu, Y., Zhou, L., et al. Epidemiological Assessment of Imported Coronavirus Disease 2019 (COVID-19) Cases in the Most Affected City Outside of Hubei Province, Wenzhou, China.JAMA Netw Open. 2020;3(4):e206785. doi:10.1001/jamanetworkopen.2020.6785

4. World Health Organization. Coronavirus disease 2019 (COVID-19) situation report137. Accessed June 7, 2020. https://www.who.int/docs/defaultsource/coronaviruse/situation-reports/20200607-covid-19-sitrep-139.pdf

5. Kurdistan Regional Government. Coronavirus (COVID-19) situation update Accessed June 7, 2020. https://gov.krd/coronavirus-en/situation-update/\#situationsummary

6. Rudaw. Coronavirus: KRG bans non-emergency travel between provinces. March 11, 2020. Accessed April 28, 2020. https://www.rudaw.net/english/kurdistan/11032020

7. Brooks, SK., Webster, RK., Smith, LE., et al. The psychological impact of quarantine and how to reduce it: rapid review of the evidence. Lancet. 2020;395(10227):912-920. doi: $\quad 10.1016 /$ S0140-6736(20)30460-8 $\quad$ https://doi.org/10.1016/S01406736(20)30460-8

8. Barbisch, D., Koenig, KL., Shih, FY. Is There a Case for Quarantine? Perspectives from SARS to Ebola. Disaster Med Public Health Prep. 2015;9(5):547-553. doi: 10.1017/dmp.2015.38

9. Reger, MA., Stanley, IH., Joiner, TE. Suicide Mortality and Coronavirus Disease 2019-A Perfect Storm? JAMA Psychiatry. Published online April 10, 2020. doi:10.1001/jamapsychiatry.2020.1060

10. Hawryluck, L., Gold, WL., Robinson, S., Pogorski, S., Galea, S., Styra, R. SARS control and psychological effects of quarantine, Toronto, Canada. Emerg Infect Dis. 2004;10(7):1206-1212. doi:10.3201/eid1007.030703

11. Cava, MA., Fay, KE., Beanlands, HJ., McCay, EA., Wignall, R. The experience of quarantine for individuals affected by SARS in Toronto. Public Health Nurs. 2005;22(5):398-406. https://doi.org/10.1111/j.0737-1209.2005.220504.x 
12. Taylor, MR., Agho, KE., Stevens, GJ., Raphael, B. Factors influencing psychological distress during a disease epidemic: data from Australia's first outbreak of equine influenza. BMC public health. 2008;8(1):347. doi:10.1186/1471-2458-8-347

13. Charlson, F., van Ommeren, M., Flaxman, A., Cornett, J., Whiteford, H., Saxena, S. New WHO prevalence estimates of mental disorders in conflict settings: a systematic review and meta-analysis. Lancet. 2019;394(10194):240-248. https://doi.org/10.1016/S0140-6736(19)30934-1

14. Seidi, PA. Assessment of the Students' Mental Health in the University of Garmian Using the Kurdish General Health Questionnaire. Passer Journal .2020;2(1): 27-31. https://doi.org/10.24271/PSR.07

15. Seidi, P., Jaff, D. Mental health in conflict settings. Lancet. 2020;394(10216):22372238. DOI:https://doi.org/10.1016/S0140-6736(19)32554-1

16. Sadik, S., Bradley, M., Al-Hasoon, S., Jenkins, R. Public perception of mental health in Iraq. Int J Ment Health Syst. 2010; 4(26). http://www.ijmhs.com/content/4/1/26

17. Hossain, MM., Sultana, A., Purohit, N. Mental health outcomes of quarantine and isolation for infection prevention: A systematic umbrella review of the global $\begin{array}{lllll}\text { evidence. } & S S R N & \text { Electron } & \text { J. } & 2020 .\end{array}$ https://papers.ssrn.com/sol3/papers.cfm?abstract_id=3561265

18. Seidi, PA. Reliability and Validity of the Kurdish version of General Health Questionnaire (K-GHQ). Journal of Garmian University. 2019; 6: 955-961. DOI:10.24271/GARMIAN.5THC63

19. Wang, Y., Xu, B., Zhao, G., Cao, R., He, X., Fu, S. Is quarantine related to immediate negative psychological consequences during the 2009 H1N1 epidemic? General hospital psychiatry. 2011;33(1):75-7. DOI: 10.1016/j.genhosppsych.2010.11.001

20. Lai, J., Ma, S., Wang, Y., et al. Factors Associated With Mental Health Outcomes Among Health Care Workers Exposed to Coronavirus Disease 2019. JAMA Netw Open. 2020;3(3): e203976. doi:10.1001/jamanetworkopen.2020.3976

21. Rometsch, C., Denkinger, J.K., Engelhardt, M., et al. Pain, somatic complaints, and subjective concepts of illness in traumatized female refugees who experienced extreme violence by the "Islamic State"(IS). J Psychosom Res. 2020:109931. DOI: 10.1016/j.jpsychores.2020.109931

22. Ahorsu, D.K., Lin, C.Y., Imani, V., Saffari, M., Griffiths, MD., Pakpour, AH. The Fear of COVID-19 Scale: Development and Initial Validation. Int J Ment Health Addict. 2020;27:1-9. doi:10.1007/s11469-020-00270-8

23. Sperber, AD. Translation and validation of study instruments for cross-cultural research. Gastroenterology. 2004; 126: 124-128. DOI:10.1053/j.gastro.2003.10.016

24. Seidi, P.A.M., Ardebil, MD., Jaff, D. COVID-19 pandemic: New challenge to securing mental well-being in conflict settings. Asian J Psychiatr. 2020; 51:102151. doi: 10.1016/j.ajp.2020.102151

25. Steinman, M.A., Perry, L., Perissinotto, CM. Meeting the Care Needs of Older Adults Isolated at Home During the COVID-19 Pandemic. JAMA Intern Med. Published online April 16, 2020. doi:10.1001/jamainternmed.2020.1661

26. Robertson, E., Hershenfield, K., Grace, SL., Stewart, DE. The psychosocial effects of being quarantined following exposure to SARS: a qualitative study of Toronto health care workers. The Canadian Journal of Psychiatry. 2004;49(6):403-7. https://doi.org/10.1177/070674370404900612

27. Rothstein, M.A., Talbott, M.K. Encouraging compliance with quarantine: a proposal to provide job security and income replacement. Am J Public Health. 2007;97 Suppl 1(Suppl 1):S49-S56. doi: 10.2105/AJPH.2006.097303

28. DiGiovanni, C., Conley, J., Chiu, D., Zaborski, J. Factors influencing compliance with quarantine in Toronto during the 2003 SARS outbreak. Biosecur Bioterror. 2004;2(4):265-272. doi:10.1089/bsp.2004.2.265

29. Johal, S.S. Psychosocial impacts of quarantine during disease outbreaks and interventions that may help to relieve strain. N Z Med J. 2009; 122(1296):4752. PMID: 19652680.

30. Kim, H.C., Yoo, S.Y., Lee, B.H., Lee, S.H., Shin, H.S. Psychiatric Findings in Suspected and Confirmed Middle East Respiratory Syndrome Patients Quarantined in Hospital: A Retrospective Chart Analysis. Psychiatry Investig. 2018;15(4):355-360. Doi:10.30773/pi.2017.10.25.1
31. Liu, X., Kakade, M., Fuller, C.J., et al. Depression after exposure to stressful events: lessons learned from the severe acute respiratory syndrome epidemic. Compr Psychiatry. 2012;53(1):15-23. doi: 10.1016/j.comppsych.2011.02.003

32. Sweeney, A., Gillard, S., Wykes, T., Rose, D. The role of fear in mental health service users' experiences: a qualitative exploration. Soc Psychiatry Psychiatr Epidemiol. 2015;50(7):1079-1087. doi: 10.1007/s00127-015-1028-Z

33. Barbera, J., Macintyre, A., Gostin, L., et al. Large-scale quarantine following biological terrorism in the United States: scientific examination, logistic and legal limits, and possible consequences. JAMA. 2001;286(21):2711-2717. doi: 10.1001/jama.286.21.2711 